\title{
EFFECT OF A NEW ULTRASHORT BETALYTIC AGENT ON ACONITINE-INDUCED ARRHYTHMIA
}

\author{
Ladislava Bartošováa, Filip Novák ${ }^{\mathrm{a}}$, Marek Frydrycha, Tomáš Parák ${ }^{\mathrm{a}}$, Radka Opatřilováb, \\ Vít Brunclík $^{c}$, Jana Kolevskác, Elnaggar El Moataz ${ }^{a}$, Jiří Nečas ${ }^{\mathrm{a}}$
}

a Department of Human Pharmacology and Toxicology,

${ }^{b}$ Department of Chemical Drugs, Pharmaceutical Faculty, University of Veterinary and Pharmaceutical Sciences, 61242 Brno, Czech Republic

c Clinic of Canine and Feline Diseases, Faculty of Veterinary Medicine, University of Veterinary and Pharmaceutical Sciences, 61242 Brno, Czech Republic

e-mail: bartosoval@vfu.cz

Received: June 10, 2005; Accepted: September 25, 2005

Key words: Experimental pharmacology/Rats/Ester-functional group/Aconitine/Ventricular fibrillations

The anti-arrhythmic effect was tested on the model of aconitine-induced arrhythmia. The experiment was performed in vivo with 31 male Wistar laboratory rats. Group A was first administered aconitine and, after the onset of the first sinus rhythm disorders, the $44 \mathrm{Bu}$ compound was administered. Group B was first administered the 44Bu compound and only after that the aconitine. The control group was administered aconitine and saline as a replacement of the tested compound. In group A, there was a decrease in the ventricular fibrillation occurrence from $100 \%$ to $8 \%$ ( $p<0.001)$ after the administration of the 44Bu compound. In the B group, the onsets of all monitored arrhythmia types were delayed by an average of $15.6 \mathrm{~min}$. Ventricular rhythm occurrence was decreased from 100 to $20 \%$, as well as ventricular fibrillations, from 100 to $0 \%(\mathrm{p}<0.001)$.

\section{INTRODUCTION}

The group of ultra-short-acting beta-blockers is becoming an important therapeutic group in the area of acute medicine in cardiovascular conditions ${ }^{1-4}$. The $44 \mathrm{Bu}$ compound, which is being tested in the authors' laboratory, belongs among the potential ultrashort acting beta-adrenolytic agents. It is an original compound which was synthesized in-house. In preliminary in vitro experiments, both compounds have been found to have the ability to block to a significant level the sodium depolarisation as well as the potassium repolarisation currents, that to larger degree than esmolol. The impact on the sodium current $\mathrm{I}_{\mathrm{Na}}$ and potassium current $\mathrm{I}_{\text {to }}$ is even more apparent than in ajmaline ${ }^{5}$. We thus decided to verify experimentally the supposed anti-arrhythmic effect of this compound in vivo on an animal. The laboratory rat used already in the preceding experiments ${ }^{6}$ was chosen.

\section{MATERIALS AND METHODS}

The anti-arrhythmic effect of the 44Bu compound was tested on the model of aconitine-induced arrhythmia. Aconitine (Sigma Aldrich) is a pentacyclic diterpenic alkaloid derived from the Aconitum napellus plant. It has a great binding affinity with the so-called "neurotoxin receptor binding site 2" of the voltage-sensitive sodium channels in the cell membranes of various excitable tissues, including the myocardium ${ }^{7-9}$.
The 44Bu compound was tested in two ways:

1. as a therapeutic agent (the experimental group A; $\mathrm{n}=12$ )

2. as a preventive agent (the experimental group B; $\mathrm{n}=10$ )

\section{Tested Substance}

The tested substance with the working title $44 \mathrm{Bu}$ belongs in the group of hydrochlorides, 2-hydroxy-3(alkylamino)propyl-4-\{(alkoxycarbonyl)amino\} benzoates and it is substituted by $n$-butyl in the basic part. The substance was synthesized at the Department of Chemical Drugs of the authors' faculty. The 44Bu compound was tested at the dose of $1.5 \mathrm{mg} . \mathrm{kg}^{-1}$ of the animal weight because in the experiments that preceded it proved to have been the most effective ${ }^{6}$ in impacting heart rate.

Aconitine was in the experiment used at a dose of $30 \mu \mathrm{g} . \mathrm{kg}^{-1}$ of the animal weight. This dose was determined based on the preliminary experiment whose object was to titrate the dose so that the survival period of the intoxicated animals verged on 5 minutes and, thus, enough time was gained for the presupposed therapeutic intervention of the tested substance.

\section{Experimental Animals}

The testing was performed in vivo in 31 male Wistar laboratory rats (average body weight of $310 \pm 25 \mathrm{~g}$ ). The animals came from and conventional breeding colony (Faculty of Medicine, Masaryk University, Brno). Methodology of the experiment was approved and moni- 
tored by the local University Ethical Committee of the UVPS Brno.

\section{Procedure}

The animals were anaesthetised using a $1 \%$ solution of ketamine (Narkamon ${ }^{\circledR}$ inj. Spofa, Czech Republic) and $2 \%$ solution of xylazine (Rometar ${ }^{\circledR}$ inj. Spofa, Czech Republic). Saline was used for dilution (sterile isotonic $0.9 \% \mathrm{NaCl}$ solution for infusion) and as a solvent of the tested substance. An anaesthetic agent was administered intramuscularly at the dose of $0.5 \mathrm{ml} / 100 \mathrm{~g}$ of body weight. The $44 \mathrm{Bu}$ compound was administered always intravenously into the uncovered vena jugularis in the following situations: (i) in case of monitoring the preventive effect (experimental group B), two minutes before the administration of aconitine, (ii) in case of monitoring the therapeutic effect (experimental group A), immediately after the development of the first sinus rhythm disorders induced by aconitine, (iii) animals in the control group $\mathrm{C}$ were administered saline intravenously in the very same moment.

Animals were being monitored continuously on a Seiva Praktik ECG machine. Experimental group A was monitored another 15 minutes following the aconitine administration; with experimental group B for 25 minutes. In predetermined time intervals (starting point, aconitine administration followed by 10 second intervals), the appropriate ECG records were made for further processing.

Changes induced by aconitine administration or by the subsequent administration of the 44Bu compound were evaluated for their potential batmotropic, dromotropic and chronotropic action. Attention was paid to the first occurrence of the given types of arrhythmias (see below) and the blockade of conduction without any close specification of the blockade type. Zero time mark is always ascribed to the intravenous aconitine administration. (The administration of aconitine took 10 seconds).

Also the percentage occurrence of the given disorder in each group was assessed discretely. Measurements of the change in the QRS complex width as well as the change in heart rate in time were done, too.

The following arrhythmia types were monitored:

- Atrial arrhythmias: supraventricular premature beats (SVPB); atrial fibrillations (AF)

- Ventricular arrhythmias: discrete ventricular premature beats or ventricular premature beats in salvos (VPBS); ventricular premature beats with a firm bond to the basic rhythm, i.e. bigeminies and trigeminies (VPBB); ventricular escape rhythm (VER) and ventricular fibrillations (VF).

\section{Statistical Analysis}

Statistical calculations of the changes of the QRS complex width and of heart rate were carried out with the Microsoft Excel software. The Student's paired t-test was used for assessing the significance of the changes as against the initial value; Student's unpaired t-test was used to determine the statistical significance of the differences among the experimental groups (A and B) and the control group (C). The Mann-Whitney test was used to verify the calculations. The statistical significance of the frequency of occurrence of the appropriate arrhythmia types was assessed with the $\varphi^{2}$ test in the Unistat 5.1 software.

\section{RESULTS}

In the control group $\mathrm{C}$, all of the 9 animals died as a result of ventricular fibrillations caused by aconitine intoxication. The average survival period of these animals was 5.1 minutes after aconitine administration. Twenty to forty seconds after the intravenous aconitine administration, the animals developed increased atrial excitability that manifested itself in supraventricular extrasystoles and, in some cases, atrial fibrillations. There was also ventricular excitability that manifested itself in ventricular extrasystoles. Extrasystoles are most commonly multiplex, discrete or in salvos. In some cases, couplets or triads of ventricular extrasystoles appear. Excitability disorders are accompanied by the blockade of the sinoatrial and conduction. There is a AV block of the 2nd and later on of the $3^{\text {rd }}$ degree. Meanwhile, the intraventricular conduction worsens, too. The QRS complex significantly widens in time and it reaches a peak of $64.7 \pm 7.5 \mathrm{~ms}$ which corresponds to $404.5 \%$ of the initial value in the fifth - the last monitored minute (Fig. 1). The rhythm source moves on the lower centres, i.e. there are atrial fibrillations and the ventricles follow their own beats - a ventricular escape rhythm appears that gradually progresses and results in some cases in ventricular fibrillation and death. Heart rate was very volatile (Fig. 2) due to the interference of positively chronotropic and negatively dromotropic effect of aconitine. The mean heart rate was throughout the whole of the experiment on the levels of $180.1 \pm 45.6 \%$ of the initial value with a peak of $246.8 \%$ (612 bpm) in the fourth minute after the i.v. aconitine administration (Fig. 2). Heart rate changes in relation to the initial value were proved by the Student's pair t-test as significant $(\mathrm{p}<0.05)$.

In experimental group A of 12 animals which were administered the tested $44 \mathrm{Bu}$ compound as a therapeutic agent, the aconitine intoxication survival balance was 9 survivals and 3 deaths. One death was dues to ventricular fibrillations, two due to total blockade of the sinoventricular as well as intraventricular conduction. The mean survival period of the 3 mortalities was 8.0 minutes after aconitine administration.

After the administration of the 44Bu compound, there is a slow down of the onset of the individual arrhythmias. The onset of the supraventricular extrasystoles is not affected because the $44 \mathrm{Bu}$ compound is administered to the animal after their development. The time of the onset of the fibrillation is prolonged by 7 seconds. The time of the first onset of all monitored ventricular arrhythmias prolongs by 29 to 66 seconds. 32 seconds later, also the SA and AV conduction blockades appear i.e.dromotropic effect of aconitine sets in (Table 1). Although in animals 


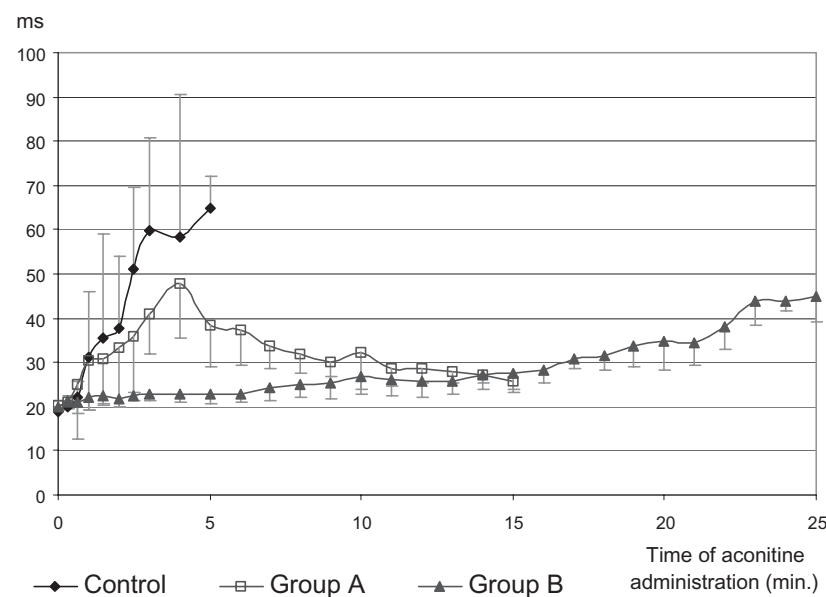

Fig. 1. Changes in the QRS complex width in time and standard deviation.

of this experimental group the ventricular escape rhythm sets in, there is no progression and it does not result in ventricular fibrillations. Instead, there is a gradual return to the individual disorders. Within 15 minutes after the i.v. aconitine administration, there is a general renewal of the sinus rhythm in $50 \%$ of the animals. In the other animals, there are also some discrete ventricular extrasystoles or supraventricular extrasystoles. What followed afterwards was not monitored. The change in the onset of the individual arrhythmia types was found to be significant $(p<0.05)$ only in the case of the onset of the ventricular rhythm - the first occurrence was prolonged by 47 seconds. Delay in the onset of the ventricular fibrillations could not have been processed statistically because this arrhythmia developed in the tested group A only once.

After the administration of the 44Bu compound, there is also a decrease in the per cent occurrence of some of the ventricular arrhythmia types (Table 1) but it was only the difference in the occurrence of the ventricular fibrillations which went down from $100 \%$ in the control group $\mathrm{C}$ to $8 \%$ in the group A that was after the assessment by the $\varphi^{2}$ test found to be statistically very significant ( $\mathrm{p}=$ 0.000032).

Since the first minute after the aconitine administration, there have been significant changes in the QRS complex width as compared to the initial value. The statistical significance $(p<0.01)$ of these changes was verified by the Student's paired t-test. The maximum QRS complex width was found in the $4^{\text {th }}$ minute when in had $48 \pm 12.6 \mathrm{~ms}$ $(234.8 \pm 62.7 \%$ of the initial value). Then, there was a slight decrease. In the $15^{\text {th }}$ minute of the experiment, the QRS complex width was at $25.7 \pm 2.4 \mathrm{~ms}$ (127.1\% of the initial value) - see Fig. 3. The Student's unpaired t-test confirmed great statistical significance $(p=0.007)$ in the fifth minute of the experiment between the QRS complex widths in the control group $\mathrm{C}$ and experimental group A animals. The statistical significance in this time interval was also confirmed by the Mann-Whitney test. It would appear, then, that the $44 \mathrm{Bu}$ compound accelerates the intraventricular conduction blocked by aconitine.

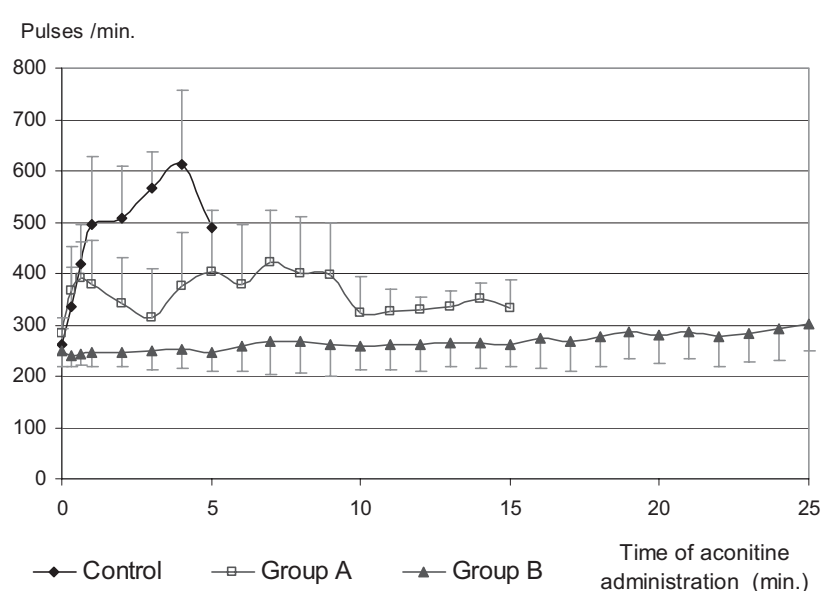

Fig. 2. Heart rate change in time and standard deviation.

The heart rate change was very volatile, similar to the control group $\mathrm{C}$. The differences as against the initial value were significant $(\mathrm{p}<0.05)$. The mean heart rate was $128.0 \pm 28.1 \%$ of the initial value during the whole of the experiment and there was a peak in the $7^{\text {th }}$ minute after the i.v. administration - 423 beat per minute $(150.0 \%$ of the initial value) - see Fig. 2. The Student's unpaired t-test as well as the Mann-Whitney test proved a great statistical significance $(p<0.01)$ of the heart rate changes in comparison with the control group $\mathrm{C}$ between the $1^{\text {st }}$ and the $4^{\text {th }}$ minute after aconitine administration.

In the experimental group B, all of the 10 experimental animals survived 25 minutes of the experiment (time measured after aconitine administration). By virtue of the preventive administration of the $44 \mathrm{Bu}$ compound, there was a highly significant $(p<0.001)$ delay of the onset of all of the monitored arrhythmia types - in average by 15.6 minutes (Table 1). The onset of the ventricular rhythm is found even as many as 21.6 minutes later. Ventricular fibrillations did not develop during the 25 minute monitoring in any of the experimental animals. There were changes also in the per cent occurrence of the individual arrhythmia types. Using the $\varphi^{2}$ test, a highly significant decrease in the occurrence of the ventricular rhythm from $100 \%$ in the control group $\mathrm{C}$ to $20 \%(\mathrm{p}=0.0004)$ and with ventricular fibrillations from $100 \%$ to 0 ( $\mathrm{p}=$ 0.000013).

Also this group manifested changes in the QRS complex width and heart rate.

Change in the QRS complex width ranged from $20.0 \pm 0.9$ to $44.9 \pm 5.8 \mathrm{~ms}(100-224.6 \%$ of the initial value) and it increased with time (Fig. 1) over the whole of the experiment. A more significant increase appears approximately in the $16^{\text {th }}$ minute. Using the Student's unpaired t-test, we were able to detect a significant difference $(p<0.05)$ in the time interval between the $1^{\text {st }}$ and $9^{\text {th }}$ minutes between the QRS complex width in the group A animals (the 44Bu compound administered as a therapeutic agent) and the group B animals (the 44Bu 
Table 1. The first occurrence of the given types of arrhythmias (minute - second) and the percentage occurrence of the given disorder in each group $(\%)$

\begin{tabular}{|c|c|c|c|c|c|c|}
\hline \multirow{2}{*}{$\begin{array}{c}\text { Type of } \\
\text { arrhythmia }\end{array}$} & \multicolumn{2}{|c|}{ Control group C n 9 } & \multicolumn{2}{c|}{ Tested group A n = 12 } & \multicolumn{2}{c|}{ Tested group B n = 10 } \\
\cline { 2 - 7 } & The time onset & Occurrence (\%) & The time onset & Occurrence (\%) & The time onset & Occurrence $\%$ ) \\
\hline SVPB & $0-29$ & $78 \%$ & $0-33$ & $67 \%$ & $14-20$ & $60 \%$ \\
\hline AF & $0-50$ & $56 \%$ & $0-57$ & $75 \%$ & $13-00$ & $20 \%$ \\
\hline VPBS & $0-45$ & $89 \%$ & $1-14$ & $75 \%$ & $17-50$ & $60 \%$ \\
\hline VPBB & $0-53$ & $56 \%$ & $1-28$ & $67 \%$ & $16-20$ & $90 \%$ \\
\hline VER & $1-23$ & $100 \%$ & $2-10$ & $83 \%$ & $23-00$ & $20 \%$ \\
\hline VF & $3-24$ & $100 \%$ & $4-30$ & $8 \%$ & $0-00$ & $0 \%$ \\
\hline Blockade & $0-52$ & $67 \%$ & $1-20$ & $67 \%$ & $15-37$ & $90 \%$ \\
\hline
\end{tabular}

$100 \%=$ total number of the tested animals in the group (n)

SVPB = supraventricular premature beats, AF = atrial fibrillations, VPBS = discrete ventricular premature beats or ventricular premature beats in salvos, VPBB = ventricular premature beats with a firm bond to the basic rhythm (bigeminies and trigeminies), $\mathrm{VER}=$ ventricular escape rhythm, $\mathrm{VF}=$ ventricular fibrillations

compound administered as a preventive agent).

Heart rate did not vary much in time. It ranged in the interval of $97-121 \%$ of the initial value and it peaked in the $25^{\text {th }}$ minute (301 bpm - Fig. 2). Using the Student's paired t-test did not return any significant heart rate changes in relation to the initial value but the unpaired t-test gave a statistically significant heart rate change compared to the control group $\mathrm{C}$ in the interval between the $20^{\text {th }}$ second and $5^{\text {th }}$ minute $(\mathrm{p}<0.01)$ and in comparison to the group $\mathrm{A}$, in the interval of the $20^{\text {th }}$ second and $2^{\text {nd }}$ minute $(\mathrm{p}<0.05)$. Statistical calculations were verified also with the Mann -Whitney test.

\section{DISCUSSION}

Effect of aconitine on the myocardium of the tested animals can be characterized as positively batmotropic, negatively dromotropic and positively chronotropic. In animals intoxicated by aconitine which were soon administered the $44 \mathrm{Bu}$ compound as a therapeutic agent (experimental group A), there was a significant decrease in the occurrence of ventricular fibrillations from $100 \%$ to $8 \%(p=0.000032)$. Total mortality dropped from $100 \%$ to $25 \%$. The $44 \mathrm{Bu}$ compound succeeded in cutting the QRS complex width from $47.98 \mathrm{~ms}$ in the $4^{\text {th }}$ minute to $25.73 \mathrm{~ms}$ in the $15^{\text {th }}$ minute and thus in speeding the intraventricular conduction in the myocardium intoxicated with aconitine (Fig. 1). The 44Bu compound also limited the increase of heart rate induced by aconitine. While in the control group $\mathrm{C}$ the heart rate was $612 \mathrm{bpm}$ in the $4^{\text {th }}$ minute, the experimental group $A$ had a heart rate of
$374 \mathrm{bpm}$ in the same time interval (Fig. 2).

When administering the $44 \mathrm{Bu}$ compound as a preventive, i.e. before the aconitine administration (experimental group B), there was a significant $(\mathrm{p}<0.001)$ delay in the onset of all of the evaluated arrhythmia types by an average of 15.6 minutes. Also, there was a greatly significant decrease in the occurrence of ventricular rhythm, from $100 \%$ to $20 \%(p=0.0004)$ and ventricular fibrillations from $100 \%$ to $0(p=0.000013)$ (Table 1$)$.

As a preventive agent, the $44 \mathrm{Bu}$ compound administration also limited the QRS complex width growth which is the opposite of what we have seen in both of the above mentioned groups. With respect to the fact that the 44Bu compound is degraded much more rapidly than aconitine the widening of the QRS complex sets in from approximately the $16^{\text {th }}$ minute, i.e. at period when first arrhythmias develop. In the tested animals of the group B, a significantly lower increase of heart rate was registered during the whole of the 25 minute experiment.

Aconitine is an alkaloid that modifies voltage-sensitive sodium channels ${ }^{10}$ most of all. It causes a permanent activation of the sodium channels at the steady state potential by blocking the inactivation of the sodium channels ${ }^{7}$. It has a great binding affinity with the so-called "neurotoxin receptor binding site 2 " which is localized on the alpha subunit in the transmembrane region of the voltage-sensitive sodium channel ${ }^{10}$. Aconitine modified sodium channels open already at a negative value of the membrane potential and as a result, there is an inhibition of their inactivation - aconitine thus permanently depolarises the membranes ${ }^{11}$. According to the in vitro data, the $44 \mathrm{Bu}$ compound should slow down the depolarisation and pro- 
long the action potential. All alkaloids binding to the socalled "neurotoxin receptor binding site 2" bind almost invariably to open channels but they affect them only slightly in both steady and inactivated state ${ }^{12}$. Preventive action of the 44Bu compound thus is founded probably on the change of the ratio of the open sodium channels and the inactivated sodium channels (i.e. in a steady state) on one side and the inactivated channels.

Modification of the sodium channel by an aconitine bonding onto the receptor binding site 2 is generally considered to be irreversible ${ }^{13}$. Despite this, some local anaesthetics, anticonvulsants and antiarrhythmics of the $1^{\text {st }}$ class can inhibit the effect of the toxins binding on the "neurotoxin receptor binding site 2" of the sodium channel ${ }^{14}$. This inhibition is probably a result of an indirect allosteric bond between the receptor binding site 2 and the receptor site for this type of drugs because both receptor sites have different bonding sites which, however, overlap ${ }^{15}$. Whether the 44Bu compound is capable of binding to the receptors of the above mentioned substances based on its structural similarity with some of the local anaesthetics (as procainamide) and of inhibiting the effect of aconitine by indirect allosteric action or whether it affects the receptor binding site 2 to which aconitine binds directly will be the subject of the next study.

\section{ACKNOWLEDGEMENT}

This work was supported by Research Project No 163700003 and No 161700002 (Ministry of Education, Youth and Sport, Czech Republic) and by the Project of the Grant Agency of the Czech Republic No 203/03/D182.

\section{REFERENCES}

1. Reilly CS, Wood M, Koshakji RP, Wood AJ. (1985) Ultra-short acting beta-blockade: a comparison with conventional beta-blockade. Clin Pharmacol Ther 38, 579-85
2. Murthy VS, Frishman WH. (1988) Controlled beta-receptor blockade with esmolol and flestolol. Pharmacotherapy 8,168-82.

3. Grohs JG, Fischer G, Raberger G. (1990) Effects of flestolol, an ultra-short acting beta-adrenoceptor antagonist, on hemodynamic changes produced by treadmill exercise or isoprenaline stimulation in conscious dogs. J Cardiovasc Pharmacol 15, 175-81.

4. Felix SB, Stangl V, Kieback A, Doerffel W, Staudt A, Wernecke KD, Baumann G, Stangl K.(2001) Acute hemodynamics effects of beta blockers in patiens with severe congestive heart failure: comparison of celiprolol and esmolol. J Cardiovasc Pharmacol 38, 666-71.

5. Bebarova M, Matejovic P, Pasek M, Simurdova M, Simurda J. (2005) Effect of ajmaline on transient outward current in rat ventricular myocytes. Gen Physiol Biophys - in print.

6. Bartosova L, Frydrych M, Hulakova G, Berankova M, Strnadova V, Mokry P, Brunclik V, Kolevska J, Bebarova M. (2004) Efficacy of Newly Synthesized, 44Bu Ultrashort-Acting, Beta-Adrenergic Antagonist to Isoprenaline-Induced Tachycardia - Comparison With Esmolol. Acta Vet Brno 73, 171-9.

7. Catterall WA. (1980) Neurotoxins that act on voltage-sensitive sodium channels in excitable membranes. Annu Rev Pharmacol Toxicol 20, 15-43.

8. Muroi M, Kimura I, Kimura M. (1990) Blocking effects of hypoaconite and aconitine on nerve action potentials in phrenic nervediaphragm muscles of mice. Neuropharmacology 29, 567-72.

9. Friese J, Gleitz J, Gutser UT, Heubach JF, Matthiesen T, Wilffert B, Selve N. (1997) Aconitum sp. Alkaloids: the modulation of voltagedependent $\mathrm{Na}+$ channels, toxicity and antinociceptive properties. Eur J Pharmacol 337, 165-74.

10. Catterall WA, Trajner V, Baden DG. (1992) Molecular properties of the sodium channel: A receptor for multiple neurotoxins. Bul Soc Pathol Exot 85, 481-5.

11. Ameri A. (1998) The effects of Aconitum alkaloids on the central nervous system. Progress in Neurobiology 56, 211-35.

12. Sterling NW. (2001) Irreversible block of human heart (hH1) sodium channels by plant alkaloid lappaconitine Mol Pharmacology 59, 183-92.

13. Hille B. Modifiers of gating. Ionic channels of excitable membranes. Sunderland, MA: Sinauer, 1992. p. 445-71.

14. Catteral WA. (1987) Common modes of drug action on $\mathrm{Na}^{+}$channels: local anaesthetics, antiarrhythmics and anticonvulsants. Trends Pharmac Sci 8, 57-65.

15. Wang SY, Wang GK. (1999) Batrachotoxin-resistant $\mathrm{Na}^{+}$channels derived from point mutations in transmembrane segment D4-S6. Biophys J 76, 3141-9. 